\title{
Conjugation and optoelectronic properties of acetylenic scaffolds and charge-transfer chromophores *
}

\author{
Milan Kivala and François Diederich ${ }^{\ddagger}$ \\ Laboratorium für Organische Chemie, ETH Zürich, Hönggerberg, $\mathrm{HCl}, \mathrm{CH}-8093$ \\ Zürich, and NCCR Nanoscale Science, Basel, Switzerland
}

\begin{abstract}
Our group started a research program in acetylene chemistry in 1987; since then, an intense research effort led to a fascinating journey into acetylenic scaffolding, aimed at exploring conjugative and optoelectronic properties of acetylenic chromophores. This journey included the generation of a unique molecular construction kit for acetylenic scaffolding, consisting of $(E)$-1,2-diethynylethenes [DEEs, $(E)$-hex-3-ene-1,5-diynes], tetraethynylethenes (TEEs, 3,4-diethynylhex-3-ene-1,5-diynes), chiral 1,3-diethynylallenes (DEAs, hepta-3,4-diene-1,6-diynes), 1,4-di and 1,1,4,4-tetraethynylbutatrienes, chiral trialkynylmethanes, and 1,1,2,2-tetraethynylethanes. These building modules were subsequently applied to the synthesis of carbon-rich architectures extending into one, two, and three dimensions. They include multinanometer-long monodisperse oligomers as models for infinite acetylenic polymers, molecular switches, perethynylated dehydroannulenes, expanded radialenes, and radiaannulenes, and an octamethoxy-substituted expanded cubane with a central $\mathrm{C}_{56}$ core. Donor-substituted cyanoethynylethenes (CEEs) and 1,1,4,4-tetracyanobuta-1,3-dienes (TCBDs) were introduced as new push-pull chromophores featuring intense intramolecular charge-transfer (CT) interactions. Dendritic multivalent CT chromophores were constructed using atom-economic, "click"-like reactions, and these systems were shown to behave as "molecular batteries", featuring exceptional electron uptake and storage capacity. The research finally led to the development of an unprecedented cascade reaction for the preparation of dendritic and oligomeric donor-acceptor (D-A) molecules. New [AB]-type oligomers become accessible in domino reactions involving repetitive sequences of $[2+2]$ cycloadditions of tetracyanoethylene (TCNE) and tetrathiafulvalene (TTF) to polyynes, followed by retro-electrocyclizations.
\end{abstract}

Keywords: alkynes; charge transfer; conjugation; annulenes; cascade reactions; cycloaddition; nonlinear optics; electrochemistry; electron reservoirs.

\section{INTRODUCTION}

Highly conjugated, carbon-rich organic molecules featuring tunable structural and optoelectronic properties have been recognized as promising candidates for use in next-generation electronic and optoelectronic devices [1-6]. Twenty years ago, in 1987, we started a research program in acetylene chemistry with the aim to synthesize acetylenic molecular carbon allotropes. While the goal of preparing and isolating new stable acetylenic forms of carbon in macroscopic quantities still remains elusive $[7,8]$, the

\footnotetext{
* Paper based on the Nozoe lecture presented at the $12^{\text {th }}$ International Symposium on Novel Aromatic Compounds (ISNA-12), 22-27 July 2007, Awaji Island, Japan. Other presentations are published in this issue, pp. 411-667.

¥Corresponding author
} 
initial objective led us to a fascinating journey into acetylenic scaffolding. In this article, we first introduce the diverse library of acetylenic building blocks that we prepared for versatile acetylenic construction in one, two, and three dimensions. Subsequently, we report how the introduction of peripheral electron-donor moieties enabled the preparation of large, stable acetylenic carbon sheets featuring intense intramolecular charge-transfer (CT) interactions. Efficient intramolecular CT is also displayed by low-molecular-weight, push-pull systems featuring new potent organic acceptors. Finally, dendritic and oligomeric CT chromophores with exceptional redox properties have become available by high-yielding additions of tetracyanoethylene (TCNE) and tetrathiafulvalene (TTF) to appropriately activated acetylenes.

\section{ACETYLENIC SCAFFOLDING-A MOLECULAR CONSTRUCTION KIT}

We developed a large library of differentially protected and functionalized carbon-rich building blocks and applied them to the assembly of various acetylenic frameworks via acetylenic couplings [9]:

i. (E)-1,2-Diethynylethenes [DEEs, (E)-hex-3-ene-1,5-diynes] and tetraethynylethenes (TEEs, 3,4-diethynylhex-3-ene-1,5-diynes) (Fig. 1) [10-14] served as starting materials for the construction of well-defined, carbon-rich molecular architectures and advanced functional materials [15-17]. Monodisperse $\pi$-conjugated poly(triacetylene) (PTA) oligomers 1a-h (Fig. 2) extending up to $18 \mathrm{~nm}$ in length (24-mer) and featuring high stability, combined with excellent solubilities in aprotic solvents, were prepared by a fast and efficient statistical deprotection-oxidative Hay oligomerization protocol starting from "macromonomers" [18,19]. We also synthesized a series of organometallic Pt(II)-bridged TEE oligomers 2a-f (Fig. 2) extending to a length of $12 \mathrm{~nm}$. In these rods, the $\mathrm{Pt}-\mathrm{C}(\mathrm{sp})$ bonds lack any $\pi$-character, and therefore the metal ions act as true insulating centers [20]. The synthesis of a new polymer bearing lateral donor-acceptor (D-A)-substituted DEE chromophores was accomplished by ring-opening metathesis polymerization (ROMP). The soluble polymer with an average of 40 monomeric units forms good optical-quality films, with the third-order susceptibility $\chi^{(3)}$ at a wavelength of $1907 \mathrm{~nm}$ being 100 times greater than that of fused silica. After electrical poling, the polymer displayed a high second-order nonlinear optical (NLO) coefficient $\left(d_{33}\right)$ [21]. TEE-based molecular switches with up to eight different states, six of which are individually addressable by light or proton stimuli, were also developed (Fig. 2) [22,23].

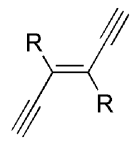

(E)-1,2-Diethynylethene

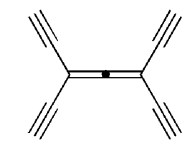

Tetraethynylallene

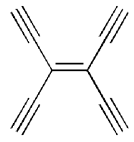

Tetraethynylethene

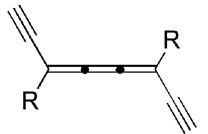

(E)-1,4-Diethynylbutatriene

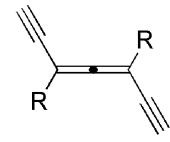

1,3-Diethynylallene

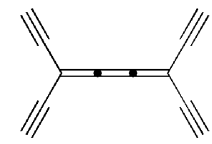

Tetraethynylbutatriene

Fig. 1 Carbon-rich building blocks for acetylenic scaffolding. 


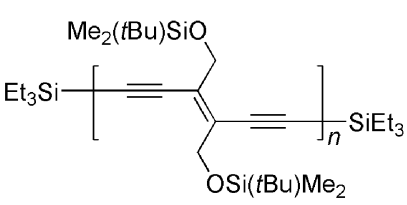

1a-h $n=1,2,4,6,8,12,16,24$

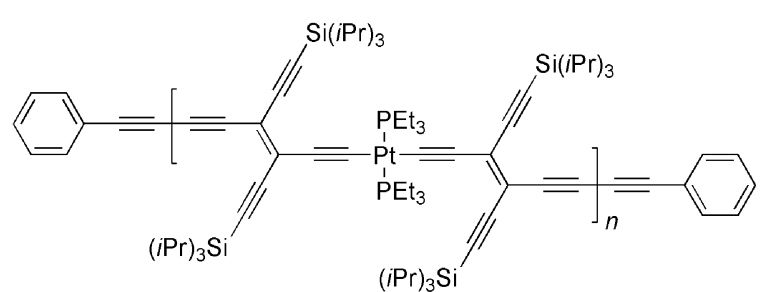

2a-f $n=1,2,3,4,5,6$

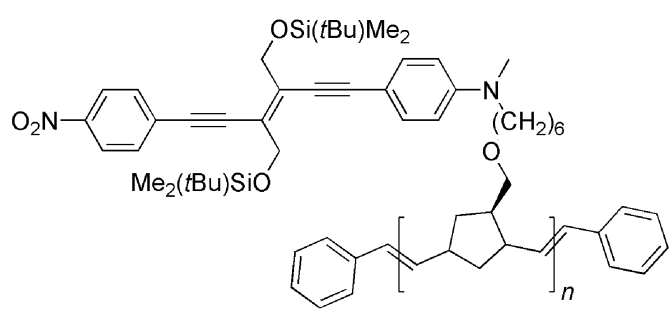

3

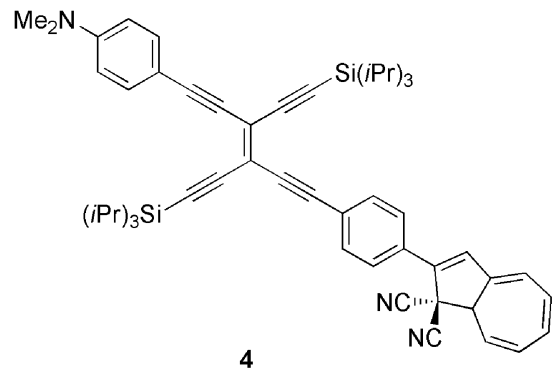

4

Fig. 2 Series of linearly conjugated monodisperse PTA oligomers 1a-h extending up to $18 \mathrm{~nm}$ in length, organometallic Pt(II)-bridged TEE oligomers $\mathbf{2 a}-\mathbf{f}$ extending to a length of $12 \mathrm{~nm}$, a new ROMP backbone polymer 3 bearing lateral donor-acceptor-substituted $(E)$-diethynylethene chromophores, and TEE-based molecular switch 4.

ii. Formal extension of the central olefinic core in DEEs and TEEs leads to 1,3-diethynylallenes (DEAs, hepta-3,4-diene-1,6-diynes) and 1,1,3,3-tetraethynylallenes (3,5-diethynylhepta3,4-dien-1,6-diynes) (Fig. 1). While 1,1,3,3-tetraethynylallenes still remain elusive due to the extreme dimerization tendency of the unprotected allene moiety, methods for the preparation of DEAs have been established [24,25]. We used a racemic mixture of DEAs for the preparationvia oxidative oligomerization - of chiral, unsaturated alleno-acetylenic macrocycles 5 and 6 (Fig. 3) [26]. Compound 5 is the first alleno-acetylenic macrocycle without aromatic rings in the backbone [27,28]. It exists as seven stereoisomers, two pairs of enantiomers, and three achiral dia-
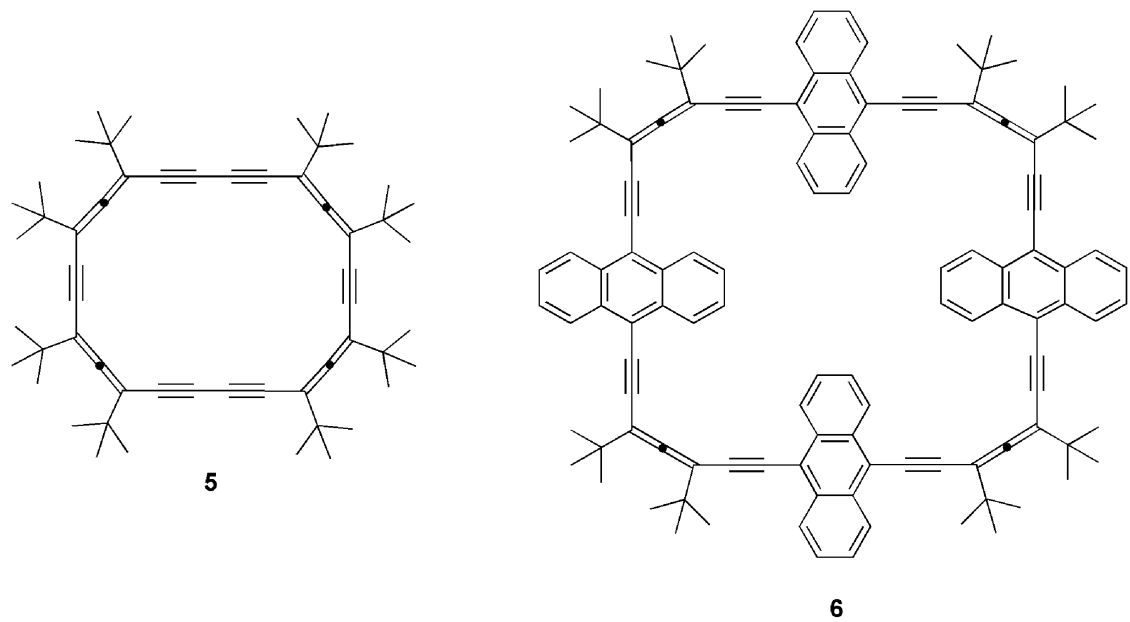

Fig. 3 Shape-persistent chiral alleno-acetylenic macrocycles 5 and $\mathbf{6}$. 
stereoisomers, which could all be isolated as pure compounds. Recently, significant progress has been made toward both optical resolution and asymmetric synthesis of chiral DEAs. Asymmetric synthesis by Pd-mediated $\mathrm{S}_{\mathrm{N}} 2$-type cross-coupling of an alkyne to an optically pure bispropargylic pentafluorobenzoate precursor yielded optically active allenes with enantioselectivities currently reaching up to $78 \%$ ee [29]. A versatile access to enantiomerically pure DEAs would be highly desirable, in particular since semi-empirical calculations (AM1) predict the formation of helical foldamers upon oxidative acetylenic coupling of homochiral monomers. Further work in this direction is currently underway.

iii. Further expansion of the central cumulenic fragment leads to 1,4-diethynyl- and 1,1,4,4-tetraethynylbutatrienes (Fig. 1) that are accessible by transition-metal-mediated dimerization of appropriate 1,1-dibromoolefins [30-32]. We found that cis-trans isomerization of differentially substituted 1,1,4,4-tetraethynylbutatrienes is remarkably facile, with barriers to rotation in the range of those for peptide bond isomerization $\left(\Delta G^{\#} \approx 20 \mathrm{kcal} \mathrm{mol}^{-1}\right)$ ! Barriers to rotation of 1,4-diethynylbutatrienes are higher $\left(\Delta G^{\#} \approx 25 \mathrm{kcal} \mathrm{mol}^{-1}\right)$, allowing in some cases the isolation of pure diastereoisomers [33].

iv. For an improved synthesis of the recently described expanded octamethoxycubane 7 with a central $\mathrm{C}_{56}$ core [34], formally obtained by inserting buta-1,3-diyne-1,4-diyl moieties into all $\mathrm{C}\left(\mathrm{sp}^{3}\right)-\mathrm{C}\left(\mathrm{sp}^{3}\right)$ bonds of octamethoxycubane [35], the preparation of optically pure trialkynylmethane building blocks as corner modules was required. Remarkably, the chirality of these compounds derives only from differential alkyne protection. The key step in the first stereoselective synthesis of the differentially silyl-protected tris(alkynyl)methyl methyl ether $(R)$-8, the first optically active trispropargylic alcohol derivative, was a diastereoselective addition of a lithium acetylide to an optically active alkynyl ketone under Cram chelation control [36]. We are now applying the optically active corner modules to an improved synthesis of expanded cubane 7 (Fig. 4), providing sufficient material for a detailed investigation of the physical properties, in particular the thermochemical quantities, of this cage compound.

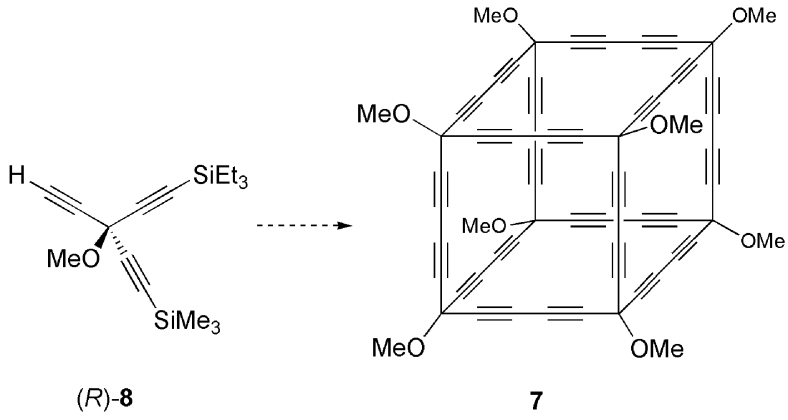

Fig. 4 Differentially silyl-protected tris(alkynyl)methyl methyl ether $(R)-8$, the first optically active trispropargylic alcohol derivative, as a corner module in the synthesis of expanded cubane 7 with a central $\mathrm{C}_{56}$ core.

\section{LARGE PERETHYNYLATED DONOR-SUBSTITUTED CARBON SHEETS}

Ever since the pioneering work by Sondheimer [37,38], acetylenic macrocycles continue to be studied both experimentally and theoretically to further enhance the understanding of aromaticity/antiaromaticity and $\pi$-conjugation in unsaturated macrocyclic systems [5,39-47]. Over the past decade, we applied TEE building blocks to the construction of novel families of acetylenic macrocycles such as perethynylated dehydroannulenes [48-51], expanded radialenes [49,52-54], and radiaannulenes combining the structural features of both dehydroannulenes and expanded radialenes [51,55]. With their extended $\pi$-chromophores, a number of representatives feature interesting optoelectronic properties, such 
as high third-order optical nonlinearities [53,54]. With their large number of sp-hybridized carbon atoms, the all-carbon cores of these macrocycles display potent electron-accepting properties and, upon peripheral donor substitution, intense intramolecular CT interactions are established.

\section{Large $N, N$-diisopropylanilino-substituted dehydroannulenes}

Among the first derivatives prepared were the per(silylethynylated) octadehydro[12]annulene 9a, with an antiaromatic macrocyclic perimeter as revealed by UV/vis and ${ }^{1} \mathrm{H}$ NMR spectroscopy, and the larger, aromatic dodecadehydro[18]annulene 10a (Fig. 5) [48,49]. Later, the terminally $N, N$-dimethylanilino (DMA)-substituted derivatives $\mathbf{9 b}$ and $\mathbf{1 0 b}$ were synthesized [50,51]. Three beneficial effects were obtained upon introduction of the peripheral $N, N$-dialkylanilino electron-donating groups:

i. Enhanced solubility of the large, carbon-rich macrocycles.

ii. Substantial stabilization of the electron-deficient all-carbon cores against nucleophilic attack and cycloadditions.

iii. Induction of strong intramolecular CT interactions between the peripheral donor groups and the electron-accepting all-carbon cores, as revealed by UV/vis spectroscopy.

In view of the appealing optoelectronic properties of donor-substituted $\mathbf{9 b}$ and $\mathbf{1 0 b}$, we prepared even larger derivatives, hexadecadehydro[20]annulene 11 and tetracosadehydro[30]annulene 12 [56]. To further enhance solubility and stability of these extended unsaturated $\pi$-chromophores and their TEE precursors, we changed from DMA to bulkier, sterically better protecting $N, N$-diisopropylanilino residues as peripheral electron-donating groups. For comparison, the $\mathrm{N}, \mathrm{N}$-diisopropylanilino-substituted [12]- and [18]annulenes $9 \mathbf{c}$ and 10c were also prepared. As a result of enhanced solubility and stability provided by the $\mathrm{N}, \mathrm{N}$-diisopropylamino groups, the yields in the oxidative macrocyclization to afford octadehydro[12]annulene 9c and dodecadehydro[18] annulene 10c were significantly improved: While the cyclization of the DMA-substituted enediyne precursor gave $\mathbf{9 b}$ and $\mathbf{1 0 b}$ in 2 and $22 \%$ yield, respectively, the transformation of the corresponding $N, N$-diisopropylanilino derivative provided $9 \mathbf{c}$ and 10c in 26 and $46 \%$ yield, respectively. Dehydro[18]annulene 10c was characterized by X-ray crystallography, revealing a practically planar macrocyclic framework, with pairs of $\mathbf{1 0 c}$ in the crystal lattice undergoing multiple intermolecular $\mathrm{C}-\mathrm{H} \cdots \pi$ interactions involving the $\mathrm{C}-\mathrm{H}$ residues of phenyl rings and acetylenic $\pi$-bonds. Oxidative Hay coupling of elongated building block $\mathbf{1 3}$, after alkyne deprotection, afforded the $N, N$-diisopropylanilino-substituted hexadecadehydro[20]annulene $\mathbf{1 1}$ and tetracosadehydro[30]annulene $\mathbf{1 2}$ in 6 and $13 \%$ yield, respectively. Both macrocycles $\mathbf{1 1}$ and $\mathbf{1 2}$ were obtained as deep-purple metallic solids that are readily soluble in chlorinated organic solvents. The stability of the rather strained dehydro[20]annulene $\mathbf{1 1}$ is limited, and it decomposes within weeks when kept in $\mathrm{CH}_{2} \mathrm{Cl}_{2}$ solution at $-20{ }^{\circ} \mathrm{C}$ in the dark. In contrast, dehydro[30]annulene 12 shows higher stability and can be kept in the solid state at $20{ }^{\circ} \mathrm{C}$ for a couple of days without decomposition. UV/vis spectroscopy furnished evidence for strong intramolecular CT interactions between the peripheral electron-donating anilino groups and the central electron-deficient cores. The intensity of the CT band in the spectra of the $4 n+2 \pi$-electron perimeters 10c and 12 is much higher than in the spectra of the $4 n$ $\pi$-electron perimeter $\mathbf{9 c}$ and $\mathbf{1 1}$, for which we do not yet have a good explanation. Electrochemical studies of the newly prepared dehydroannulenes confirmed the electron-accepting power of their all-carbon cores. Careful analysis provided indications that the antiaromatic systems $\mathbf{9 c}$ and $\mathbf{1 1}$ are more readily reduced than their aromatic counterparts $10 \mathbf{c}$ and 12, in agreement with previous findings [57].

During the characterization of all four $N, N$-diisopropylanilino-substituted dehydroannulenes 9c, 10c, 11, and 12 (Fig. 5) by ${ }^{1} \mathrm{H}$ NMR spectroscopy in $\mathrm{CDCl}_{3}$, no concentration dependence of the chemical shifts of the aromatic protons was observed. This indicates the absence of macrocyclic self-association within the studied concentration range $(0.1-5.0 \mathrm{mM})$, in agreement with the electronic absorption behavior which fully obeys the Lambert-Beer law. 

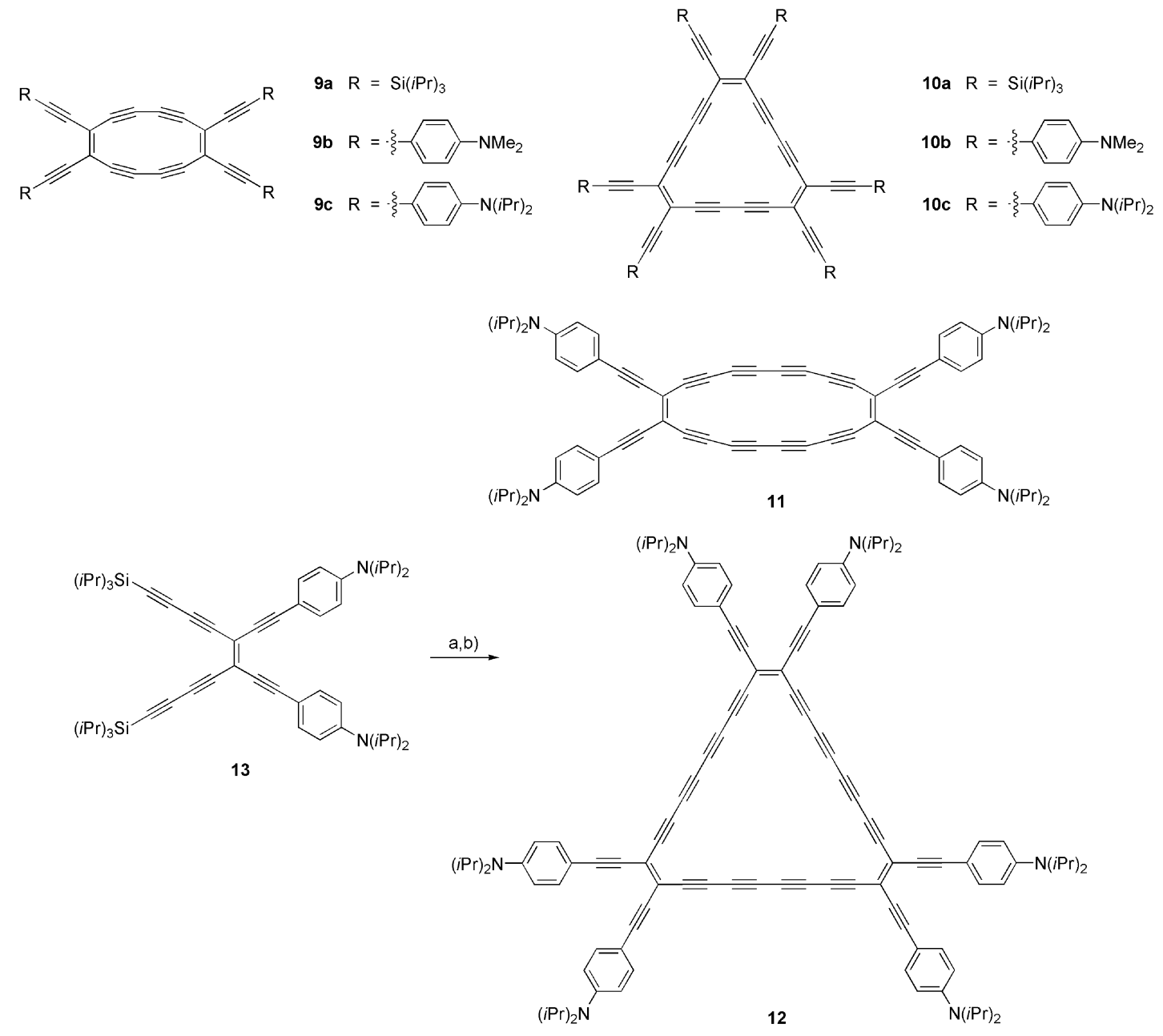

Fig. 5 Donor-substituted dehydroannulenes 9 and 10. Synthesis of dehydroannulenes 11 and 12. (a) $n \mathrm{Bu}_{4} \mathrm{NF}, \mathrm{THF}$, $15 \mathrm{~min}, 0{ }^{\circ} \mathrm{C}$; (b) $\mathrm{CuCl}$, TMEDA, $\mathrm{O}_{2}$, acetone, $2 \mathrm{~h}, 20{ }^{\circ} \mathrm{C}, 6 \%(\mathbf{1 1}), 13 \%$ (12) (yields over two steps). THF = tetrahydrofuran; TMEDA $=N, N, N^{\prime}, N^{\prime}$-tetramethylethylenediamine.

\section{Nonaggregating tris(tetrathiafulvaleno)dodecadehydro[18]annulene}

TTF and its derivatives are strong $\pi$-electron donors that have been studied for more than three decades as components of organic molecular conductors [58-60], and as redox-active units in supramolecular chemistry [58,61]. Acetylenic scaffolding starting from ethynylated TTF derivatives afforded extended conjugated materials with promising optoelectronic properties [58,62]. We prepared the new tris(tetrathiafulvaleno)dodecadehydro[18]annulene 14, bearing six peripheral $n$-hexyl substituents, by oxidative Glaser-Hay cyclization of diethynylated TTF, obtained by deprotection of precursor 15 (Fig. 6) [63]. In contrast to the oxidative couplings of cis-bisdeprotected TEEs, as described above [48-51], the formation of cyclic dimers was not observed. Apparently, annellation of the five-membered TTF rings prevents the large distortion of the inner $\mathrm{C}(\mathrm{sp})-\mathrm{C}=\mathrm{C}$ bond angles that is necessary for formation of the strained cyclic dimer, as revealed by X-ray crystallographic analysis of per(silylethynyl)ated octadehydro[12]annulene [48,49]. According to both ${ }^{1} \mathrm{H}$ NMR and UV/vis spectroscopy studies, macrocycle $\mathbf{1 4}$ shows no aggregation in solution. The intense violet color of $\mathbf{1 4}$ is accordingly assigned to an intramolecular rather than an intermolecular CT transition. 


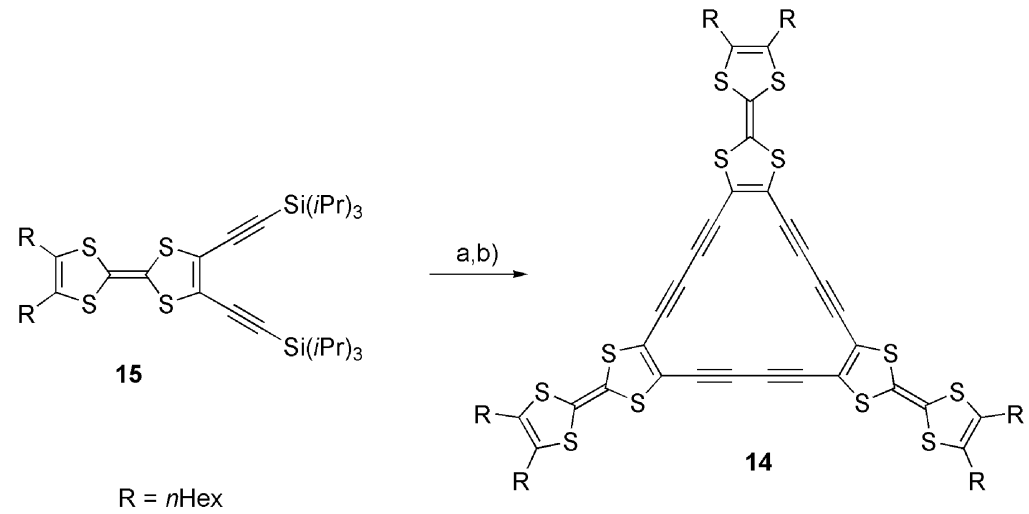

Fig. 6 Synthesis of tris(tetrathiafulvaleno)dodecadehydro[18]annulene 14. (a) $n \mathrm{Bu}_{4} \mathrm{NF}, \mathrm{THF}, 0{ }^{\circ} \mathrm{C}$; (b) $\mathrm{CuCl}$, TMEDA, $\mathrm{CH}_{2} \mathrm{Cl}_{2}, \mathrm{O}_{2}, 0{ }^{\circ} \mathrm{C}, 47 \%$ (yield over two steps).

This nonaggregating behavior contrasts that of similar tris-TTF-fused dehydro[18]annulenes containing six peripheral carboxylic ester $\left(\mathrm{CO}_{2} n \mathrm{Bu}, \mathrm{CO}_{2} n \mathrm{Oct} ; \mathrm{Bu}=\right.$ butyl, Oct = octyl $)$ substituents. Iyoda and coworkers demonstrated in elegant work that these ester derivatives undergo $\pi$-stacking self-assembly in benzene and toluene [64]. The ester groups render the entire $\pi$-chromophore more electrondeficient, which favors $\pi$-stacking. These groups also extend the $\pi$-conjugated perimeter, and, most importantly, may additionally facilitate the aggregation by intermolecular dipolar $\mathrm{C}=\mathrm{O} \cdots \mathrm{C}=\mathrm{O}$ interactions [65]. Taken together, the two studies $[63,64]$ show that aromatic $\pi$-stacking self-assembly can be strongly enhanced by additional peripheral intermolecular dipolar interactions, a principle which should find further use in supramolecular construction.

\section{CHARGE-TRANSFER CHROMOPHORES INCORPORATING NEW POTENT ORGANIC ACCEPTORS}

Molecular and polymeric D-A chromophores have attracted much attention due to their highly polarized $\pi$-conjugated chromophores, resulting in efficient second- and third-order nonlinear optical (NLO) effects [66-68]. Tuning physical properties to enhance specific NLO effects by simply modifying the chemical structure represents a significant advantage of using organic push-pull chromophores. It is well known that the molecular first-order hyperpolarizability $(\beta)$ depends not only on the strength of the donor and acceptor groups, but also on the nature of the $\pi$-conjugated spacer through which they interact. While well-defined guidelines to enhance $\beta$ (and the bulk second-order susceptibility $\chi^{(2)}$ ) have been established, definite principles for achieving high molecular second-order hyperpolarizability $(\gamma)$ and high-bulk third-order susceptibility $\left(\chi^{(3)}\right)$ are still being pursued $[3,69]$.

\section{Cyanoethynylethenes: Property tuning in charge-transfer chromophores}

In earlier work, we had prepared a new class of intramolecular CT chromophores by decorating the TEE framework (Fig. 1) with strong electron donors, such as DMA, and acceptors, such as 4-nitrophenyl moieties $[3,12,70]$. Some of these compounds were shown to feature high second- and third-order optical nonlinearities. We subsequently turned our attention to increasing the strength of the electron acceptors to further enhance the push-pull effects and the NLO properties.

The first class of potent electron acceptors, which we developed, are the cyanoethynylethenes (CEEs), of which only two derivatives had been reported previously [71,72]. CEEs are hybrid derivatives combining the synthetic versatility of TEEs for the construction of $\pi$-conjugated scaffolds with the 
powerful electron-accepting properties of cyanoalkenes such as TCNE [TCNE; $E_{1, \text { red }}=-0.32 \mathrm{~V}$,

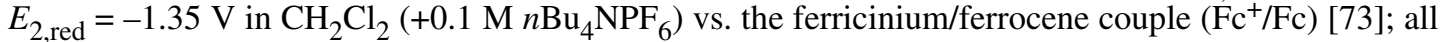
potentials in this review are measured under these conditions using cyclic voltammetry $(\mathrm{CV})$ or rotating disc voltammetry (RDV)] (Fig. 7). Initially, we prepared silylated CEEs such as 16a-c (Fig. 7) and extended CEE dimers such as 16d [74]. A dramatic increase in electron-acceptor strength was observed upon the replacement of one $\mathrm{RC} \equiv \mathrm{C}-$ by an isoelectronic $\mathrm{N} \equiv \mathrm{C}$ - group (average anodic shift of the first reduction potential: $380 \mathrm{mV}$ ) or upon substituting $\mathrm{RC} \equiv \mathrm{C}-\mathrm{C}-\mathrm{C} \equiv \mathrm{CR}$ by $\mathrm{NC}-\mathrm{C}-\mathrm{CN}$ moieties (average anodic shift of the first reduction potential: $830 \mathrm{mV}$ !). Thus, dimer $16 \mathbf{d}\left(E_{1 \text {,red }}=-0.57 \mathrm{~V}\right)$ approaches the acceptor strength of TCNE. It should be noted that CEEs are rather delicate, highly reactive, electrophilic chromophores that undergo readily conjugate additions with nucleophiles such as amines and alcohols.

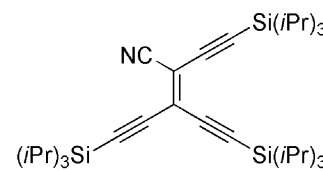

$16 a$ $E_{1, \text { red }}-1.58 \mathrm{~V}$<smiles>N#C/C(C#C[AsH2])=C(/C#N)C#C[AsH2]</smiles>

16b<smiles>N#CC(C#N)=C(C#N)[Se][Ba]</smiles>

$16 \mathrm{c}$

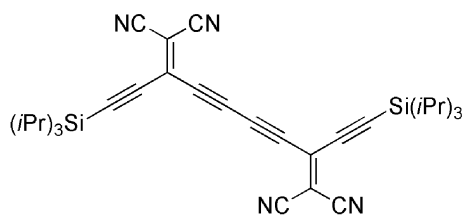

16d

$E_{1, \text { red }}-1.25 \mathrm{~V}$

$E_{1, \text { red }}-0.72 \mathrm{~V}$

$E_{1, \text { red }}-0.57 \mathrm{~V}$

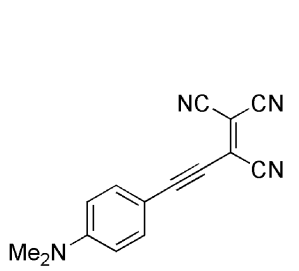

$17 \mathrm{a}$

$E_{1, \text { red }}-0.85 \mathrm{~V}$

$\lambda_{\max } 591 \mathrm{~nm}(2.10 \mathrm{eV})$<smiles>CN(C)c1ccc(C#CC(C#Cc2ccc(N(C)C)cc2)=C(C#N)C#N)cc1</smiles>

$17 b$

$$
E_{1, \text { red }}-1.38 \mathrm{~V}
$$$$
\lambda_{\max } 563 \mathrm{~nm}(2.20 \mathrm{eV})
$$<smiles>CNc1ccc(C#CC(C#CC#CC(C#Cc2ccc(N(C)C)cc2)=C(C#N)C#N)=C(C#N)C#N)cc1</smiles>

$17 d$

$$
\begin{aligned}
& E_{1, \text { red }}-0.74 \mathrm{~V} \\
& \lambda_{\max } 600 \mathrm{~nm}(2.07 \mathrm{eV})
\end{aligned}
$$

Fig. 7 Examples of monomeric and dimeric CEEs. Given are the reversible first one-electron reduction potentials $E_{1, \text { red }}(\mathrm{V})$ in $\mathrm{CH}_{2} \mathrm{Cl}_{2}\left(+0.1 \mathrm{M} n \mathrm{Bu}_{4} \mathrm{NPF}_{6}\right.$, vs. $\left.\mathrm{Fc}^{+} / \mathrm{Fc}\right)$ and the maxima of the $\mathrm{CT}$ bands $\lambda_{\max }\left(\mathrm{nm}\right.$ and eV) in $\mathrm{CHCl}_{3}$.

Further functionalization with DMA donor groups stabilizes the CEE chromophores dramatically: they loose their reactivity against nucleophiles and become thermally stable. Push-pull derivatives, such as 17a-d (Fig. 7) feature strong intramolecular CT interactions resulting in intense, 
bathochromically shifted CT bands in the UV/vis spectra [75,76]. The DMA moieties possess high quinoid character, as revealed by X-ray crystallography for $\mathbf{1 7} \mathbf{a}$ and $\mathbf{1 7} \mathbf{b}$, confirming efficient intramolecular CT from the donor to the acceptor moieties.

In a comprehensive study [76], useful guidelines for tuning the optical gap of strong push-pull systems were established. Thus, it was found that the bathochromic shift of the CT band in the UV/vis spectrum is not an appropriate measure for the efficiency of $\mathrm{D}-\mathrm{A} \pi$-conjugation in the ground state. Rather, ground-state data such as NMR chemical shifts, bond length alternation, and quinoid character of aromatic rings in X-ray crystal structures, redox potentials, or theoretical calculations $[77,78]$ need to be used to evaluate this efficiency. We observed for the donor-substituted CEEs that more efficient D-A conjugation leads to larger optical gaps [76,77]. Smaller optical gaps (i.e., more bathochromically shifted CT bands) are obtained by reducing the efficiency of D-A conjugation through introduction of spacers, such as alkenes or alkynes. The UV/vis data correlate perfectly with the electrochemical data: at strong D-A conjugation, the HOMO (highest occupied molecular orbital) of the donor is lowered and the LUMO (lowest unoccupied molecular orbital) of the acceptor raised, yielding a large optical gap. In the case at weaker ground-state D-A conjugation (i.e., when donor and acceptor are separated by larger spacers), the energy levels of HOMO and LUMO resemble those in the free components and a smaller optical gap (bathochromically shifted CT band) is measured.

This was nicely confirmed in the study of a series of D-A chromophores 18-23 in which the unsaturated spacer between DMA donor and $\mathrm{C}(\mathrm{CN})_{2}$ acceptor moieties was systematically varied (Fig. 8) [79]. The UV/vis spectra of the chromophores feature intense bathochromically shifted CT bands with the lowest-energy transitions and the smallest optical gap being measured for the two-dimensionally extended chromophores 23a and 23b with multiple D-A conjugation pathways. In the series of $\mathbf{1 8 b}, \mathbf{1 9 b}$, $\mathbf{2 1 b}$, and 22b, the size of the spacer is gradually extended and the electrochemical HOMO-LUMO gap, calculated as the difference between first oxidation and reduction potentials $\left[\Delta\left(E_{1, \mathrm{ox}}-E_{1, \text { red }}\right)\right]$, decreases steadily from $1.94 \mathrm{~V}(\mathbf{1 8 b})$ to $1.53 \mathrm{~V}(\mathbf{2 2 b})$. At the same time, the optical gap as determined from the end-absorption of the UV/vis spectra changes from $\lambda_{\text {end }}=655 \mathrm{~nm}(1.89 \mathrm{eV} ; \mathbf{1 8 b})$ to $785 \mathrm{~nm}(1.58 \mathrm{eV}$; 22b). This decrease in electrochemical and optical gaps is a direct consequence of the reduction in the D-A conjugation with increasing spacer length [76].

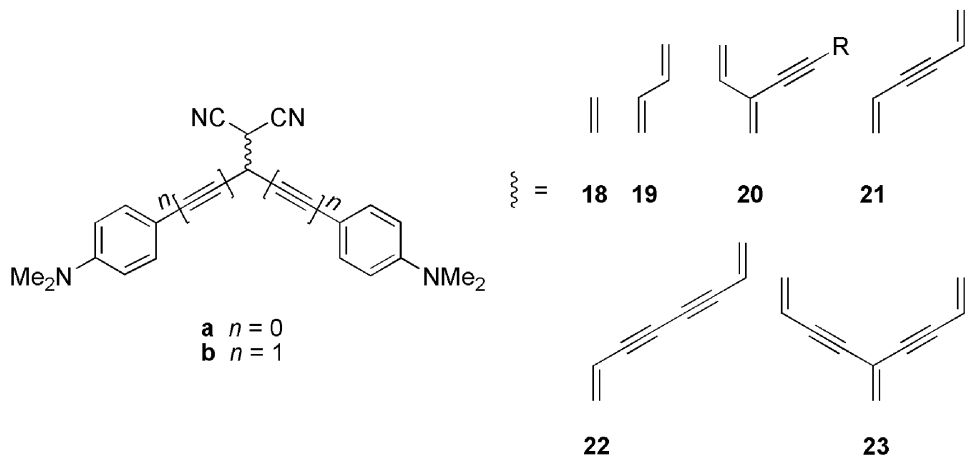

Fig. 8 A new class of DMA-substituted CEEs 18-23 to explore the donor-acceptor conjugation and NLO properties as a function of the spacer between donor and acceptor moieties.

All of the CT chromophores described above are thermally stable, some of them up to $250{ }^{\circ} \mathrm{C}$. Most of them can be sublimed undecomposed, thus allowing thin film formation by vapor-phase deposition for nanoscale device applications. A high-quality crystalline thin film (ca. $20 \mathrm{~nm}$ thickness) of donor-substituted CEE 17a was vacuum-deposited on highly oriented pyrolytic graphite (HOPG) [80]. In this film, molecules of 17a stack with a favorable antiparallel molecular dipole orientation and an interchromophoric distance of $3.44 \AA$. The structure of the crystalline thin film was solved by transmis- 
sion electron microscopy (TEM) electron diffraction and shown to be identical to the previously determined X-ray crystal structure. Nanoscale data recording into the crystalline film by scanning tunneling microscopy (STM; tungsten tip) yielded dots featuring an average diameter of $2.1 \mathrm{~nm}$, which amounts to a possible storage density of $10^{13}$ bits $\mathrm{cm}^{-2}$. The formation of these dots is explained by intermolecular, electric field-induced CT in stacks of $\mathbf{1 7} \mathbf{a}$.

The third-order NLO properties of donor-substituted CEEs 17a-d $[81,82]$ and push-pull chromophores 18-23 [83] were investigated. Degenerate four-wave mixing (DFWM) experiments revealed extraordinarily large third-order optical nonlinearities, relative to the small molecular mass of these molecules, that are within a factor of 50 from the predicted fundamental limit [84]. At the off-resonance wavelength of $1.5 \mu \mathrm{m}$, the rotational average of the third-order molecular polarizability $\gamma_{\text {rot }}=53 \pm 13 \times$ $10^{-48} \mathrm{~m}^{5} \mathrm{~V}^{-2}\left(3.8 \times 10^{-33} \mathrm{esu}\right)$ was highest for dimeric CEE 17d, which corresponds to $1.7 \times 10^{-48} \mathrm{~m}^{5}$ $\mathrm{V}^{-2}$ per delocalized electron [81]. Appealing NLO properties, together with their environmental stability make these compounds very promising for applications in optoelectronic devices.

\section{Donor-substituted 1,1,4,4-tetracyanobuta-1,3-dienes: Charge-transfer chromophores by atom-economic synthesis}

Recently, we introduced a new class of powerful CT chromophores, donor-substituted 1,1,4,4-tetracyanobuta-1,3-dienes (TCBDs) such as 24-26 (Fig. 9), accessible in often quantitative yields in an atom-economic synthesis [85] by formal [2+2] cycloaddition between TCNE and donor-substituted alkynes, followed by electrocyclic ring-opening of the initially formed cyclobutenes $[86,87]$. The $[2+2]$ cycloaddition of TCNE with electron-rich metal acetylides, followed by retro-electrocyclization to give organometallic TCBD derivatives had actually been described by Bruce and coworkers as early as 1981 $[88,89]$, but the corresponding reaction with electron-rich alkynes had not been systematically explored $[90,91]$.

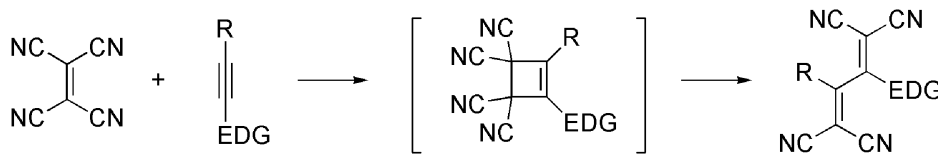

$E D G=$ electron-donating group<smiles>CN(C)c1ccc(C(C=C(C#N)C#N)=C(C#N)C#N)cc1</smiles>

$24(97 \%)$

$E_{1, \text { red }}-0.69 \mathrm{~V}$

$\lambda_{\max } 570 \mathrm{~nm}(2.18 \mathrm{eV})$<smiles>CN(C)c1ccc(C(=C(C#N)C#N)C(=C(C#N)C#N)c2ccc(N(C)C)cc2)cc1</smiles>

$25(100 \%)$

$E_{1, \text { red }}-1.06 \mathrm{~V}$

$\lambda_{\max } 470 \mathrm{~nm}(2.64 \mathrm{eV})$<smiles>CN(C)c1ccc(C#CC(=C(C#N)C#N)C(=C(C#N)C#N)c2ccc(N(C)C)cc2)cc1</smiles>

$26(96 \%)$

$E_{1, \text { red }}-0.89 \mathrm{~V}$

$\lambda_{\max } 526 \mathrm{~nm}(2.36 \mathrm{eV})$

Fig. 9 Examples of donor-substituted TCBDs 24-26 prepared in quantitative yield by [2+2] cycloaddition of TCNE to donor substituted alkynes, followed by retro-electrocyclization of the intermediately formed cyclobutene. Given are the reversible first one-electron reduction potentials $E_{1 \text {,red }}(\mathrm{V})$ in $\mathrm{CH}_{2} \mathrm{Cl}_{2}\left(+0.1 \mathrm{M} n \mathrm{Bu}_{4} \mathrm{NPF}_{6}\right.$, vs. $\left.\mathrm{Fc}^{+} / \mathrm{Fc}\right)$ and the maxima of the $\mathrm{CT}$ bands $\lambda_{\text {max }}\left(\mathrm{nm}\right.$ and $\mathrm{eV}$ ) in $\mathrm{CH}_{2} \mathrm{Cl}_{2}$. 
Donor-substituted TCDBs are thermally stable up to $300{ }^{\circ} \mathrm{C}$, as determined by thermogravimetric analysis (TGA), and can be sublimed without decomposition. Despite the nonplanarity of these chromophores, evidenced by a series of X-ray crystallographic analyses, efficient intramolecular CT interactions are observed. The crystal structures show high quinoid character for the DMA rings, and the UV/vis spectra feature intense, bathochromically shifted CT bands with maxima between 450 and $800 \mathrm{~nm}$. Large third-order optical nonlinearities (e.g., for 26: $\gamma_{\text {rot }}=12 \pm 2 \times 10^{-48} \mathrm{~m}^{5} \mathrm{~V}^{-2}$ ), paired with high stability and easy accessibility, make donor-substituted TCBDs attractive chromophores for the fabrication of optoelectronic devices $[82,86]$. The TCBD moiety is a potent electron acceptor: despite DMA-donor substitution, the first one-electron reduction of 24 in $\mathrm{CH}_{2} \mathrm{Cl}_{2}$ occurs at $-0.69 \mathrm{~V}$.

The electrochemical properties of oligomeric and dendritic donor-substituted TCBDs (Fig. 10) are particularly remarkable. Thus, the trimeric derivative $\mathbf{2 7}$ undergoes six reversible one-electron reduction steps, each centered on a dicyanovinyl moiety, in the narrow potential range between -0.69 and $-1.69 \mathrm{~V}$ [87] (Fig. 10). Note that the six reduction steps of fullerene $\mathrm{C}_{60}$, a potent electron acceptor, in $\mathrm{MeCN} /$ toluene occur over a much wider potential range between -0.98 and $-3.26 \mathrm{~V}$ ( $\mathrm{vs}^{\mathrm{F}} \mathrm{Fc}^{+} / \mathrm{Fc}$ ) [92]. This finding stimulated our search for even larger multivalent CT systems acting as potent molecular electron reservoirs.

Compared to 27, buta-1,3-diyne-1,4-diyl instead of ethyne-1,2-diyl fragments were used to attach the $N, N$-dihexylanilino (DHA) substituents to the central core to (i) reduce steric crowding and (ii) enhance the distance between pairs of $\mathrm{C}(\mathrm{CN})_{2}$ moieties, thereby bringing the individual reduction potentials even closer. TCNE addition, having the character of a "click"-reaction, afforded dendrimer-like TCBD derivatives such as $\mathbf{2 8}$ and $\mathbf{2 9}$ in excellent yields of 77 and $86 \%$, respectively (Fig. 10) [93]. All compounds are environmentally stable and melt undecomposed above $100{ }^{\circ} \mathrm{C}$. Detailed electrochemical investigation by $\mathrm{CV}$ and RDV revealed general redox characteristics of multivalent donor-substituted TCBDs:

i. All DHA moieties in the multivalent systems are oxidized in a single reversible multi-electron transfer, denoting that they all behave as independent redox centers [94]. As an example, dendrimer 29 is oxidized in a unique $12 \mathrm{e}^{-}$transfer step at $+0.89 \mathrm{~V}$.

ii. Each TCBD moiety accommodates two electrons. Consequently, a large number of reversible electron uptakes, centered on the dicyanovinyl units, are observed. For example, dendrimer 29 with 12 TCBD moieties accepts 24 electrons in two reversible $12 \mathrm{e}^{-}$reduction steps within an exceptionally narrow potential range between -0.70 and $-1.10 \mathrm{~V}$.

We found $\mathrm{C} \equiv \mathrm{C}$ bonds adjacent to the electron-accepting TCBD units to be activated for the [2+2] cycloaddition to the strong electron donor TTF. This reaction of TTF, which is followed by retro-electrocyclization to give 1,2-di(1,3-dithiol-2-ylidene)ethane moieties, had previously been described by Hopf and coworkers and Hirsch and coworkers for CEEs and $\alpha, \omega$-dicyanopolyynes, respectively $[95,96]$. This finding led to the construction of a new class of conjugated [AB]-type oligomers via a cascade of sequential TCNE/TTF additions to end-capped polyynes, controlled by the electronic properties of the reacting $\mathrm{C} \equiv \mathrm{C}$ bonds. In this cascade, 1,2-di(1,3-dithiol-2-ylidene)ethane fragments are the donor parts activating adjacent triple bonds for TCNE addition, whereas TCBD moieties provide the activation for TTF addition. Thus, mono-DMA-, mono-phenyl-substituted tetrayne $\mathbf{3 0}$ yielded, upon stepwise treatment with TCNE and TTF, the regular [AB]-type oligomer $\mathbf{3 1}$ as a thermally stable, black metallic solid. This research culminated in a one-pot, eight-step, five-component domino reaction, with the formation of a single product, A-D-A-D chromophore 31, resulting from four sequential cycloaddition/retro-electrocyclizations of TCNE and TTF molecules to oligoyne 30 (Fig. 11) [93].

The formation of regular $[\mathrm{AB}]$-type sequences is the result of a careful control of the electronic character of the involved acetylenic triple bonds. New types of extended CT chromophores featuring interesting advanced materials properties should in the future become available by such one-pot reactions, by simply mixing a polyyne with the appropriate donor and acceptor components, such as TCNE and TTF.

(C) 2008 IUPAC, Pure and Applied Chemistry 80, 411-427 


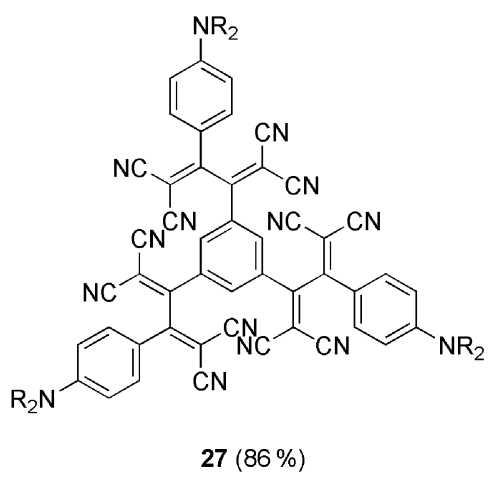

$\mathrm{R}=\mathrm{C}_{6} \mathrm{H}_{13}$

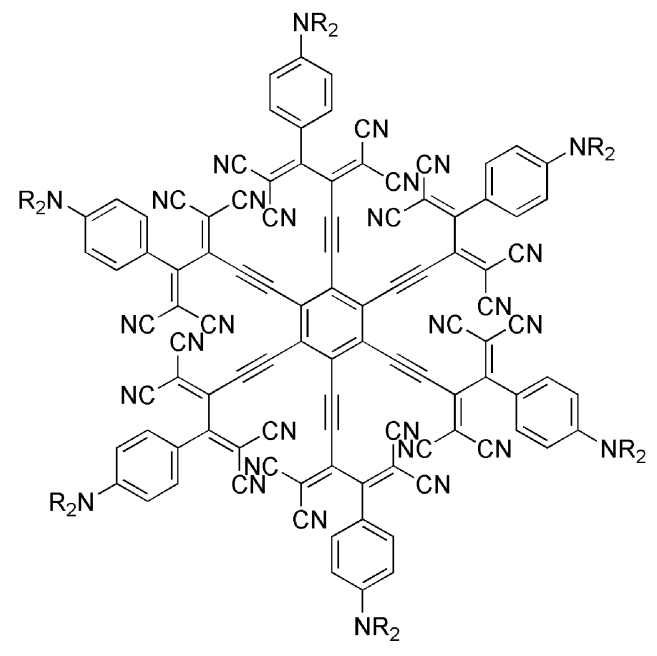

$28(77 \%)$

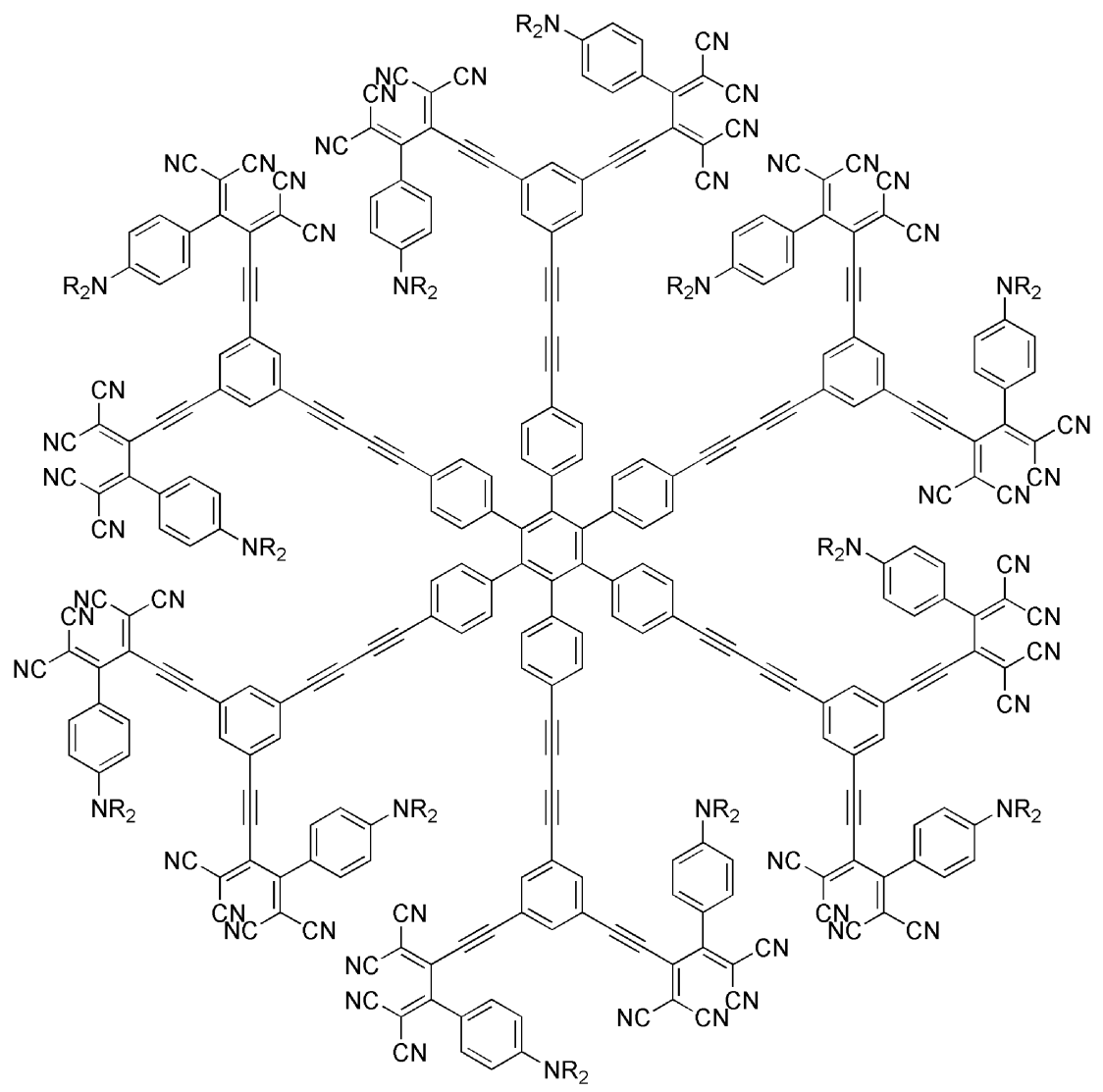

$29(86 \%)$

Fig. 10 Dendrimer-like donor-substituted TCBDs capable of taking up 6 (27), 12 (28), and 24 (29) electrons in a narrow potential range under electrochemical conditions. Given in parentheses are the yields of the [2+2] cycloaddition/retro-electrocyclization sequences starting from the donor-substituted alkyne precursors and TCNE. 


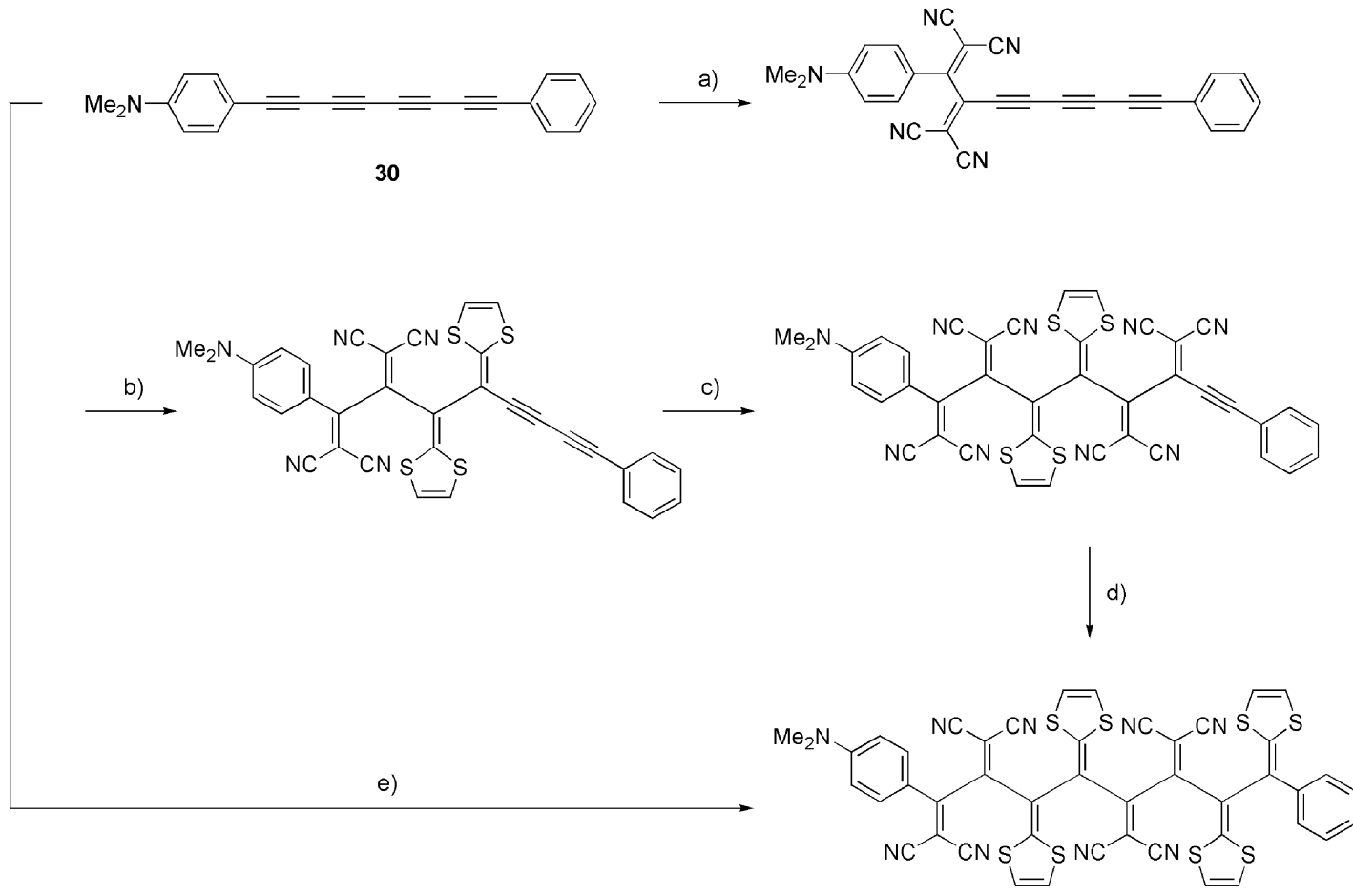

31

Fig. 11 Cascade of alternating [2+2] cycloadditions/retro-electrocyclizations of TCNE/TTF starting from octatetrayne 30. (a) TCNE, $\mathrm{CH}_{2} \mathrm{Cl}_{2}, 14 \mathrm{~h}, 20^{\circ} \mathrm{C}, 95 \%$; (b) TTF, $\mathrm{MeCN}, 17 \mathrm{~h}, 60{ }^{\circ} \mathrm{C}, 78 \%$; (c) $\mathrm{TCNE} \mathrm{CH}_{2} \mathrm{Cl}_{2}$, $22 \mathrm{~h}, 20^{\circ} \mathrm{C}, 92 \%$; (d) TTF, $\mathrm{CH}_{2} \mathrm{Cl}_{2} / \mathrm{MeCN} 1: 1,3 \mathrm{~h}, 50{ }^{\circ} \mathrm{C}, 21 \%$ (31); (e) TCNE, TTF, $\mathrm{CH}_{2} \mathrm{Cl}_{2} / \mathrm{MeCN} 1: 1,22 \mathrm{~h}$, $50{ }^{\circ} \mathrm{C}, 21 \%(31)$.

\section{CONCLUSION}

This review describes a journey through novel molecular architectures that are constructed by acetylenic scaffolding starting from a unique library of small building modules. On the fundamental scientific side, important experimental insight into the efficiency of $\pi$-electron conjugation in acetylenic chromophores has been gained, and this has already provided substantial stimulation to advanced computational study $[78,97,98]$. Oxidative coupling in two dimensions has yielded large carbon sheets such as perethynylated dehydroannulenes, expanded radialenes, and radiaannulenes. Starting from unique chiral building blocks, DEAs and trialkynylmethanes, three-dimensional architectures such as an expanded cubane with a $\mathrm{C}_{56}$ core and alleno-acetylenic macrocycles have become available. Pushing the limits in size and complexity of functional carbon-rich systems will continue to be at the center of our program in acetylene chemistry. Investigations of the larger, carbon-rich systems at the level of single molecules and their potential to form nanopatterned functional surfaces are just at the beginning [99].

On the other hand, this synthesis-driven research increasingly addresses highly programmed, functional chromophores for application in optoelectronic devices. New strong electron donors such as CEEs and TCBDs have been introduced, and their conjugation to organic donors has provided push-pull chromophores featuring desirable properties such as (i) versatile synthesis, (ii) high environmental stability allowing thin film formation by vapor deposition, (iii) intense bathochromically shifted CT bands, (iv) electrochemical reductions at potentials approaching those of the benchmark compounds TCNE and TCNQ (7,7,8,8-tetracyanoquinodimethane), and (v) large third-order optical nonlinearities. 
At the same time, comprehensive study has established general structural guidelines for predicting and tuning the optical gap of strong D-A chromophores. This research so far has culminated in the preparation of dendrimer-like, multivalent $\mathrm{CT}$ chromophores acting as a type of molecular batteries that are capable of taking up an exceptional number of electrons. Finally, a one-pot protocol for cascade TCNE/TTF additions to polyynes, controlled by the electronic properties of individual acetylenic triple bonds, has opened up an easy access to a new class of [AB]-type oligomers and polymers. In future work, we intend to explore the application of these unique push-pull systems in advanced, energy-saving technologies.

\section{ACKNOWLEDGMENTS}

We thank the NCCR "Nanoscale Science", Basel, the ETH Research Council, and the German Fonds der Chemischen Industrie for continuing support of this work. This interdisciplinary research would clearly not have been possible without the bold contributions of numerous collaborators; their names are listed in the cited references.

\section{REFERENCES}

1. J. M. Tour. Chem. Rev. 96, 537 (1996).

2. F. Diederich. Chem. Commun. 219 (2001).

3. R. R. Tykwinski, U. Gubler, R. E. Martin, F. Diederich, C. Bosshard, P. Günter. J. Phys. Chem. B 102, 4451 (1998).

4. M. B. Nielsen, F. Diederich. In Modern Arene Chemistry, D. Astruc (Ed.), pp. 196-216, Wiley$\mathrm{VCH}$, Weinheim (2002).

5. F. Diederich, P. J. Stang, R. R. Tykwinski (Eds.). Acetylene Chemistry. Chemistry, Biology and Material Science, Wiley-VCH, Weinheim (2005).

6. S. R. Forrest, M. E. Thompson (Eds.). Special issue on "Organic Electronics and Optoelectronics": Chem. Rev. 107, 923-1386 (2007).

7. F. Diederich. Nature 369, 199 (1994).

8. U. H. F. Bunz, Y. Rubin, Y. Tobe. Chem. Soc. Rev. 28, 107 (1999).

9. P. Siemsen, R. C. Livingston, F. Diederich. Angew. Chem., Int. Ed. 39, 2632 (2000).

10. J. Anthony, A. M. Boldi, Y. Rubin, M. Hobi, V. Gramlich, C. B. Knobler, P. Seiler, F. Diederich. Helv. Chim. Acta 78, 13 (1995).

11. R. R. Tykwinski, M. Schreiber, R. P. Carlón, F. Diederich, V. Gramlich. Helv. Chim. Acta 79, 2249 (1996).

12. R. R. Tykwinski, M. Schreiber, V. Gramlich, P. Seiler, F. Diederich. Adv. Mater. 8, 226 (1996).

13. R. R. Tykwinski, F. Diederich. Liebigs Ann./Recueil 649 (1997).

14. M. B. Nielsen, F. Diederich. Chem. Rev. 105, 1837 (2005).

15. M. B. Nielsen, F. Diederich. Synlett 4, 544 (2002).

16. M. B. Nielsen, F. Diederich. Chem. Rec. 2, 189 (2002).

17. J.-P. Gisselbrecht, N. N. P. Moonen, C. Boudon, M. B. Nielsen, F. Diederich, M. Gross. Eur. J. Org. Chem. 2959 (2004).

18. R. E. Martin, U. Gubler, J. Cornil, M. Balakina, C. Boudon, C. Bosshard, J.-P. Gisselbrecht, F. Diederich, P. Günter, M. Gross, J.-L. Brédas. Chem.—Eur. J. 6, 3622 (2000).

19. M. J. Edelmann, M. A. Estermann, V. Gramlich, F. Diederich. Helv. Chim. Acta 84, 473 (2001).

20. P. Siemsen, U. Gubler, C. Bosshard, P. Günter, F. Diederich. Chem.-Eur. J. 7, 1333 (2001).

21. J.-M. Raimundo, S. Lecomte, M. J. Edelmann, S. Concilio, I. Biaggio, C. Bosshard, P. Günter, F. Diederich. J. Mater. Chem. 14, 292 (2004).

22. L. Gobbi, P. Seiler, F. Diederich. Angew. Chem., Int. Ed. 38, 674 (1999). 
23. L. Gobbi, P. Seiler, F. Diederich, V. Gramlich, C. Boudon, J.-P. Gisselbrecht, M. Gross. Helv. Chim. Acta 84, 743 (2001).

24. R. C. Livingston, L. R. Cox, V. Gramlich, F. Diederich. Angew. Chem., Int. Ed. 40, 2334 (2001).

25. R. C. Livingston, L. R. Cox, S. Odermatt, F. Diederich. Helv. Chim. Acta 85, 3052 (2002).

26. S. Odermatt, J. L. Alonso-Gómez, P. Seiler, M. M. Cid, F. Diederich. Angew. Chem., Int. Ed. 44, $5074(2005)$

27. S. Thorand, F. Vögtle, N. Krause. Angew. Chem., Int. Ed. 38, 3721 (1999).

28. M. D. Clay, A. G. Fallis. Angew. Chem., Int. Ed. 44, 4039 (2005).

29. M. K. J. ter Wiel, S. Odermatt, P. Schanen, P. Seiler, F. Diederich. Eur. J. Org. Chem. 3449 (2007).

30. J.-D. van Loon, P. Seiler, F. Diederich. Angew. Chem., Int. Ed. Engl. 32, 1187 (1993).

31. M. Iyoda, H. Otani, M. Oda, Y. Kai, Y. Baba, N. Kasai. J. Am. Chem. Soc. 108, 5371 (1986).

32. A. Auffrant, F. Diederich, C. Boudon, J.-P. Gisselbrecht, M. Gross. Helv. Chim. Acta 87, 3085 (2004).

33. A. Auffrant, B. Jaun, P. D. Jarowski, K. N. Houk, F. Diederich. Chem.-Eur. J. 10, 2906 (2004).

34. P. Manini, W. Amrein, V. Gramlich, F. Diederich. Angew. Chem., Int. Ed. 41, 4339 (2002).

35. P. E. Eaton. Angew. Chem., Int. Ed. Engl. 31, 1421 (1992).

36. V. Convertino, P. Manini, W. B. Schweizer, F. Diederich. Org. Biomol. Chem. 4, 1206 (2006).

37. F. Sondheimer. Acc. Chem. Res. 5, 81 (1972).

38. M. Nakagawa. Angew. Chem., Int. Ed. Engl. 18, 202 (1979).

39. S. Eisler, R. R. Tykwinski. Angew. Chem., Int. Ed. 38, 1940 (1999).

40. J. A. Marsden, M. M. Haley. J. Org. Chem. 70, 10213 (2005).

41. A. Nomoto, M. Sonoda, Y. Yamaguchi, T. Ichikawa, K. Hirose, Y. Tobe. J. Org. Chem. 71, 401 (2006).

42. I. Hisaki, M. Sonoda, Y. Tobe. Eur. J. Org. Chem. 833 (2006).

43. V. Maraval, R. Chauvin. Chem. Rev. 106, 5317 (2006).

44. E. L. Spitler, C. A. Johnson II, M. M. Haley. Chem. Rev. 106, 5344 (2006).

45. K. Nakao, M. Nishimura, T. Tamachi, Y. Kuwatani, H. Miyasaka, T. Nishinaga, M. Iyoda. J. Am. Chem. Soc. 128, 16740 (2006).

46. T. Kawase, Y. Nishiyama, T. Nakamura, T. Ebi, K. Matsumoto, H. Kurata, M. Oda. Angew. Chem., Int. Ed. 46, 1086 (2007).

47. K. Tahara, T. Yoshimura, M. Sonoda, Y. Tobe, R. V. Williams. J. Org. Chem. 72, 1437 (2007).

48. J. Anthony, C. B. Knobler, F. Diederich. Angew. Chem., Int. Ed. Engl. 32, 406 (1993).

49. J. Anthony, A. M. Boldi, C. Boudon, J.-P. Gisselbrecht, M. Gross, P. Seiler, C. B. Knobler, F. Diederich. Helv. Chim. Acta 78, 797 (1995).

50. F. Mitzel, C. Boudon, J.-P. Gisselbrecht, M. Gross, F. Diederich. Chem. Commun. 2318 (2002).

51. F. Mitzel, C. Boudon, J.-P. Gisselbrecht, P. Seiler, M. Gross, F. Diederich. Helv. Chim. Acta 87, 1130 (2004).

52. A. M. Boldi, F. Diederich. Angew. Chem., Int. Ed. Engl. 33, 468 (1994).

53. M. Schreiber, R. R. Tykwinski, F. Diederich, R. Spreiter, U. Gubler, C. Bosshard, I. Poberaj, P. Günter, C. Boudon, J.-P. Gisselbrecht, M. Gross, U. Jonas, H. Ringsdorf. Adv. Mater. 9, 339 (1997).

54. M. B. Nielsen, M. Schreiber, Y. G. Baek, P. Seiler, S. Lecomte, C. Boudon, R. R. Tykwinski, J.-P. Gisselbrecht, V. Gramlich, P. J. Skinner, C. Bosshard, P. Günter, M. Gross, F. Diederich. Chem.-Eur. J. 7, 3263 (2001).

55. F. Mitzel, C. Boudon, J.-P. Gisselbrecht, P. Seiler, M. Gross, F. Diederich. Chem. Commun. 1634 (2003).

56. M. Kivala, F. Mitzel, C. Boudon, J.-P. Gisselbrecht, P. Seiler, M. Gross, F. Diederich. Chem. Asian J. 1, 479 (2006).

57. C. Boudon, J.-P. Gisselbrecht, M. Gross, J. Anthony, A. M. Boldi, R. Faust, T. Lange, D. Philp, J.-D. Van Loon, F. Diederich. J. Electroanal. Chem. 394, 187 (1995). 
58. J. L. Segura, N. Martín. Angew. Chem., Int. Ed. 40, 1372 (2001).

59. P. Batail (Ed.). Special issue on "Molecular Conductors": Chem. Rev. 104, 4887-5782 (2004).

60. M. A. Herranz, L. Sánchez, N. Martín. Phosphorus, Sulfur Silicon Relat. Elem. 180, 1133 (2005).

61. M. Frei, F. Diederich, R. Tremont, T. Rodriguez, L. Echegoyen. Helv. Chim. Acta 89, 2040 (2006).

62. M. B. Nielsen, N. F. Utesch, N. N. P. Moonen, C. Boudon, J.-P. Gisselbrecht, S. Concilio, S. P. Piotto, P. Seiler, P. Günter, M. Gross, F. Diederich. Chem.—Eur. J. 8, 3601 (2002).

63. A. S. Andersson, K. Kilså, T. Hassenkam, J.-P. Gisselbrecht, C. Boudon, M. Gross, M. B. Nielsen, F. Diederich. Chem.-Eur. J. 12, 8451 (2006).

64. H. Enozawa, M. Hasegawa, D. Takamatsu, K. Fukui, M. Iyoda. Org. Lett. 8, 1917 (2006).

65. R. Paulini, K. Müller, F. Diederich. Angew. Chem., Int. Ed. 44, 1788-1805 (2005).

66. S. R. Marder, B. Kippelen, A. K.-Y. Jen, N. Peyghambarian. Nature 388, 845 (1997).

67. H. Ma, S. Liu, J. Luo, S. Suresh, L. Liu, S. H. Kang, M. Haller, T. Sassa, L. R. Dalton, A. K.-Y. Jen. Adv. Funct. Mater. 12, 565 (2002).

68. S. R. Mader. Chem. Commun. 131 (2006).

69. J.-L. Brédas, C. Adant, P. Tackx, A. Persoons. Chem. Rev. 94, 243 (1994).

70. R. Spreiter, C. Bosshard, G. Knöpfle, P. Günter, R. R. Tykwinski, M. Schreiber, F. Diederich. J. Phys. Chem. B 102, 29 (1998).

71. H. Hopf, M. Kreutzer. Angew. Chem., Int. Ed. 29, 393 (1990).

72. L. Dulog, B. Körner, J. Heinze, J. Yang. Liebigs Ann. 1663 (1995).

73. C. Diaz, A. Arancibia. Polyhedron 19, 137 (2000).

74. N. N. P. Moonen, C. Boudon, J.-P. Gisselbrecht, P. Seiler, M. Gross, F. Diederich. Angew. Chem., Int. Ed. 41, 3044 (2002).

75. N. N. P. Moonen, R. Gist, C. Boudon, J.-P. Gisselbrecht, P. Seiler, T. Kawai, A. Kishioka, M. Gross, M. Irie, F. Diederich. Org. Biomol. Chem. 1, 2032 (2003).

76. N. N. P. Moonen, W. C. Pomerantz, R. Gist, C. Boudon, J.-P. Gisselbrecht, T. Kawai, A. Kishioka, M. Gross, M. Irie, F. Diederich. Chem.-Eur. J. 11, 3325 (2005).

77. N. N. P. Moonen, F. Diederich. Org. Biomol. Chem. 2, 2263 (2004).

78. I. Fernández, G. Frenking. Chem. Commun. 5030 (2006).

79. F. Bureš, W. B. Schweizer, J. C. May, C. Boudon, J.-P. Gisselbrecht, M. Gross, I. Biaggio, F. Diederich. Chem.-Eur. J. 13, 5378 (2007).

80. G. Jiang, T. Michinobu, W. Yuan, M. Feng, Y. Wen, S. Du, H. Gao, L. Jiang, Y. Song, F. Diederich, D. Zhu. Adv. Mater. 17, 2170 (2005).

81. J. C. May, J. H. Lim, I. Biaggio, N. N. P. Moonen, T. Michinobu, F. Diederich. Opt. Lett. 30, 3057 (2005).

82. J. C. May, P. R. LaPorta, B. Esembeson, I. Biaggio, T. Michinobu, F. Bureš, F. Diederich. Proc. of SPIE 6331, 633101/1 (2006).

83. J. C. May, I. Biaggio, F. Bureš, F. Diederich. Appl. Phys. Lett. 90, 251106/1 (2007).

84. M. G. Kuzyk. Opt. Lett. 25, 1183 (2000).

85. B. M. Trost. Science 254, 1471 (1991).

86. T. Michinobu, J. C. May, J. H. Lim, C. Boudon, J.-P. Gisselbrecht, P. Seiler, M. Gross, I. Biaggio, F. Diederich. Chem. Commun. 737 (2005).

87. T. Michinobu, C. Boudon, J.-P. Gisselbrecht, P. Seiler, B. Frank, N. N. P. Moonen, M. Gross, F. Diederich. Chem.-Eur. J. 12, 1889 (2006).

88. M. I. Bruce, J. R. Rodgers, M. R. Snow, A. G. Swincer. J. Chem. Soc., Chem. Commun. 271 (1981).

89. T. Mochida, S. Yamazaki. J. Chem. Soc., Dalton Trans. 3559 (2002).

90. C. Cai, I. Liakatas, M.-S. Wong, M. Bösch, C. Bosshard, P. Günter, S. Concilio, N. Tirelli, U. W. Suter. Org. Lett. 1, 1847 (1999).

91. Y. Morioka, N. Yoshizawa, J.-i. Nishida, Y. Yamashita. Chem. Lett. 33, 1190 (2004). 
92. Q. Xie, E. Pérez-Cordero, L. Echegoyen. J. Am. Chem. Soc. 114, 3978 (1992).

93. M. Kivala, C. Boudon, J.-P. Gisselbrecht, P. Seiler, M. Gross, F. Diederich. Angew. Chem., Int. Ed. 46, 6357 (2007).

94. M.-C. Daniel, J. Ruiz, J.-C. Blais, N. Daro, D. Astruc. Chem.-Eur. J. 9, 4371 (2003).

95. H. Hopf, M. Kreutzer, P. G. Jones. Angew. Chem., Int. Ed. Engl. 30, 1127 (1991).

96. G. Schermann, O. Vostrowsky, A. Hirsch. Eur. J. Org. Chem. 2491 (1999).

97. P. D. Jarowski, F. Diederich, K. N. Houk. J. Org. Chem. 70, 1671 (2005).

98. P. D. Jarowski, F. Diederich, K. N. Houk. J. Phys. Chem. A 110, 7237 (2006).

99. D. Bonifazi, A. Kiebele, M. Stöhr, F. Cheng, T. Jung, F. Diederich, H. Spillmann. Adv. Funct. Mater. 17, 1051 (2007). 